\title{
Differential effects of repetition on pre- and postcategorical memory traces*
}

\author{
JOSEPH J. DALEZMAN and HARVEY G. SHULMAN $\dagger$ \\ Ohio State University, Columbus, Ohio 43210
}

\begin{abstract}
The effect of list repetition on immediate recall for aurally presented nine-letter lists was studied under two conditions. In the first, a redundant stimulus item was presented as the tenth item in each list, while the suffix was not included in a control condition. As in previous research (Crowder \& Morton, 1969), the stimulus suffix selectively interfered with recall at the terminal presentation serial positions, indicating the presence of precategorical acoustic storage. Repetition had a nonselective effect on performance. This result and an analysis of acoustic errors support the inference that qualitative differences in the memory code may lead to differences in other functional properties of the memory trace, such as responsiveness to repetition.
\end{abstract}

The concept of modality-specific memory was introduced into the recent literature by Sperling (1960), who focused on the visual information store (VIS). Crowder and Morton (1969) later reported results supporting the inference of an auditory analogue to VIS. Because the level of coding in this system seemed prelinguistic, Crowder and Morton named the auditory memory "precategorical acoustic storage" (PAS).

Both VIS and PAS have been conceived of as memory systems distinct from each other and from systems such as the short-term store (STS) which receives information from the sensory memories. Recently, Craik and Lockhart (1972) have proposed an alternative conceptualization of human memory in which differences in retention characteristics are associated with qualitative differences in the memory code, rather than with a set of distinct memory systems such as VIS, PAS, and STS. At the present time, there is little hard evidence available with which to choose between these two viewpoints, and the question addressed by the present experiment could equally well be phrased in terms of effects on traces residing in PAS or on traces encoded at a precategorical acoustic level.

Of interest in the present experiment was the effect of repetition on the retention of information coded at two different levels, typically associated with PAS and STS. In immediate recall experiments, repetition has been shown by Hebb (1961), Melton (1963), and others to facilitate retention. In these experiments the stimuli were digit strings and were most likely encoded categorically in terms of phonemic content. The behavioral effects of PAS have most often been observed in a modification of the immediate recall procedure in which a redundant stimulus item, called the suffix, is

*This research was supported by Grants 2-TO1-MH-08526-09 and 5-RO1-MH-20495 from the National Institutes of Mental Health.

tReprint requests should be sent to the second author at the Human Performance Center, 404B West 17 th Avenue, Columbus, Ohio 43210 . presented on each trial as the final item in the recall list. When a suffix condition is compared to a nonsuffix control, a depressed recall level is noted for the most recently presented items. This stimulus suffix effect is assumed to reflect the displacement of acoustic information from PAS. The magnitude of the suffix effect, then, is related to the amount of information available in PAS at the time of recall.

The strategy of the present experiment was to observe performance in a stimulus suffix experiment as a function of list repetition. Repetition should strengthen the trace associated with STS, as in Hebb (1961) and Melton (1963), resulting in increased retention at all serial positions in the list. An effect of repetition on PAS traces should be localized at the most recently presented list positions and would lead to an increasingly larger suffix effect as number of repetitions increased.

\section{METHOD}

\section{Design}

Three major independent variables-serial position, repetition, and presence vs absence of the suffix-were combined factorially within Ss. Each $S$ was given four blocks of 16 immediate recall trials. The suffix and control conditions alternated between blocks in an ABAB pattern for half of the Ss and in a BABA pattern for the other half. Within each block, four different lists were aurally presented, each for four consecutive recall trials. In the control condition a list of nine letters was presented on each trial, and in the suffix condition a tenth letter, the letter " $\mathrm{A}$ " on every trial, was added to each list. Each list was constructed by sampling nine letters without replacement from the following 13-letter vocabulary: B, F, G, H, J, K, L, N, Q, R, W, X, Z.

\section{Procedure}

Stimulus lists were recorded on magnetic tape in a monotone male voice at a rate of two letters/sec, followed by a $30-\mathrm{sec}$ blank recall interval. Each list was preceded by the word "ready." Written recall, signaled by the end of list presentation, was recorded on a nine-position vertical grid. The 13-letter vocabulary was displayed to each $S$ during the entire course of the experiment. Instructions included the statement that a recalled item would be scored as correct only if it were recorded 


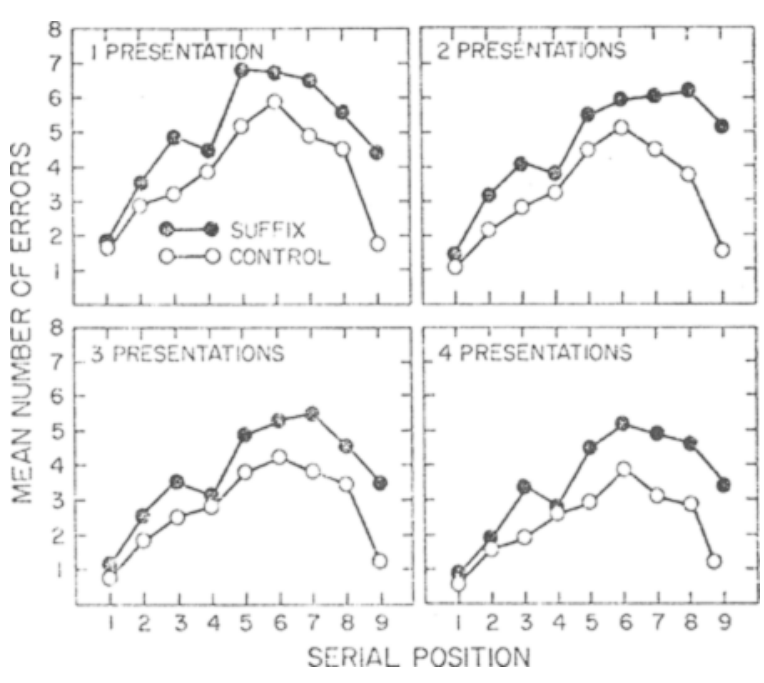

Fig. 1. Mean number of errors (eight possible) in recall as a function of serial position.

in the grid position corresponding to its position in the presented list. Prior to each block, the Ss were told whether or not the redundant suffix would be presented during the next set of trials. Recall of the suffix was not required.

\section{Subjects}

Sixty undergraduate students at Ohio State University, fulfilling a requirement for their general psychology course, served as Ss. They were run in groups of five Ss.

\section{RESULTS}

Figure 1 shows the recall results plotted separately for each list repetition. Analysis of variance revealed significant main effects of serial position $[F(8,472)=102.68, p<.001]$, repetition $[F(3,177)=119.22, p<.001]$, and suffix conditions $[F(1,59)=200.01, p<.001]$. The first two effects merely signify the replication of previously reported and well known results. The interaction of suffix condition with serial position was also significant $[F(8,472)=20.68, p<.001]$, indicating the presence of the interaction upon which the inference of PAS storage is generally based. A significant interaction between repetition and serial position was obtained $[F(24,1416)=3.50, p<.001]$, reflecting the smaller effect of repetition at the ends of the list than at the middle positions. The effect of repetition on the serial position curve did not differ between the suffix and control conditions, indicating that repetition had no influence on the strength of PAS traces. This inference is based on the finding of a nonsignificant interaction between serial position, repetition, and suffix conditions $[F(24,1416)=1.35]$. However, the stability of the data (with $\mathrm{N}=480$ observations per point) would seem to indicate acceptance of the null hypothesis.

Table 1 presents the error data, partitioned into three categories: omissions, position errors, and acoustic confusion errors. Position errors were defined as recalls of correct letters within two serial positions of their correct location. A fourth category of errors including intrusions and remote position errors is not shown in Table 1. Furthermore, position errors and acoustic errors are not mutually exclusive categories since, for example, transpositions of acoustically confusible letters sometimes occurred in recall. The data for omissions and position errors resemble the data for total errors, showing both the suffix effect and repetition effects, although the latter are not shown in Table 1. The data for acoustic confusions are plotted separately for each list presentation in Fig. 2. For Serial Positions 1-4 these data also resemble the total error data, insofar as the control conditions showed fewer errors than the suffix conditions. For the last half of the list, however, this pattern is reversed, with more acoustic confusions occurring in the control lists. An analysis of variance performed on acoustic confusion scores revealed significant main effects of suffix condition $[\mathrm{F}(1,59)=5.76, \mathrm{p}<.05]$ and serial position $[F(8,472)=22.07, \quad p<.001]$ and a significant interaction between these two factors $[F(8,472)=32.51, p<.001]$. Neither the main effect of repetition nor any interactions with repetition were significant in these data. Acoustic error rates were also computed as a proportion of the total error rates. The most interesting feature of these data was the fact that in the control condition acoustic confusions represented a substantial proportion of the errors made at the last serial position. Thus, at the final serial position over the four list presentations, acoustic errors represented .59 , $.60, .72$, and .66 of the total error rate. In contrast, the comparable proportions for the suffix condition were $.11, .13, .11$, and .11 .

\section{DISCUSSION}

The purpose of the present experiment was to compare the effects of repetition on memory traces coded at two different levels. The manipulation used to produce different levels of coding was the use of the

Table 1

Mean Number of Errors Averaged Over List Repetitions (S = Suffix, C = Control)

\begin{tabular}{|c|c|c|c|c|c|c|c|c|}
\hline \multirow[b]{3}{*}{ Position } & & & \multicolumn{4}{|c|}{ Error Category } & & \\
\hline & \multicolumn{2}{|c|}{ Omissions } & \multicolumn{2}{|c|}{ Position } & \multicolumn{2}{|c|}{ Acoustic } & \multicolumn{2}{|c|}{ Total } \\
\hline & $\mathbf{S}$ & $\mathrm{C}$ & $\mathrm{S}$ & $\mathrm{C}$ & $S$ & $\mathrm{C}$ & $\mathrm{S}$ & $\mathrm{C}$ \\
\hline 1 & .27 & .23 & .27 & .21 & .40 & .18 & 1.35 & 1.04 \\
\hline 2 & .35 & .29 & 1.20 & .94 & .64 & .45 & 2.75 & 2.18 \\
\hline 3 & .58 & .47 & 1.56 & 1.27 & .94 & .51 & 3.95 & 2.60 \\
\hline 4 & .70 & .51 & 1.49 & 1.53 & .70 & .33 & 3.47 & 3.13 \\
\hline 5 & 1.89 & 1.57 & 1.79 & 1.48 & .66 & .74 & 5.43 & 4.05 \\
\hline 6 & 2.29 & 1.80 & 1.64 & 2.02 & .58 & 1.15 & 5.80 & 4.78 \\
\hline 7 & 2.34 & 1.19 & 1.95 & 1.88 & .70 & .98 & 5.70 & 4.07 \\
\hline 8 & 1.63 & .82 & 2.16 & 1.49 & .41 & 1.06 & 5.00 & 3.65 \\
\hline 9 & 1.12 & .33 & 1.11 & .45 & .44 & .93 & 3.79 & 1.46 \\
\hline
\end{tabular}


stimulus suffix procedure. The interpretation of the recall advantage afforded the control condition at the terminal list positions in this procedure is that information at a precategorical acoustic level is available to supplement the recall based on postcategorical codes. The latter type of code is the sole source of recall in the suffix condition. The pattern of acoustic errors found in our results is completely consistent with this hypothesis. Acoustic confusions were the only type of error that occurred more frequently in the control than in the suffix condition, and this was true only at the serial positions for which information in PAS should be present.

The finding that recall of control lists shows an advantage at the earlier input positions cannot be deduced directly from hypothetical properties of PAS. This result has also been found in several of Crowder's experiments with the suffix effect (e.g., Crowder, 1969) and may reflect a lack of independence between recall

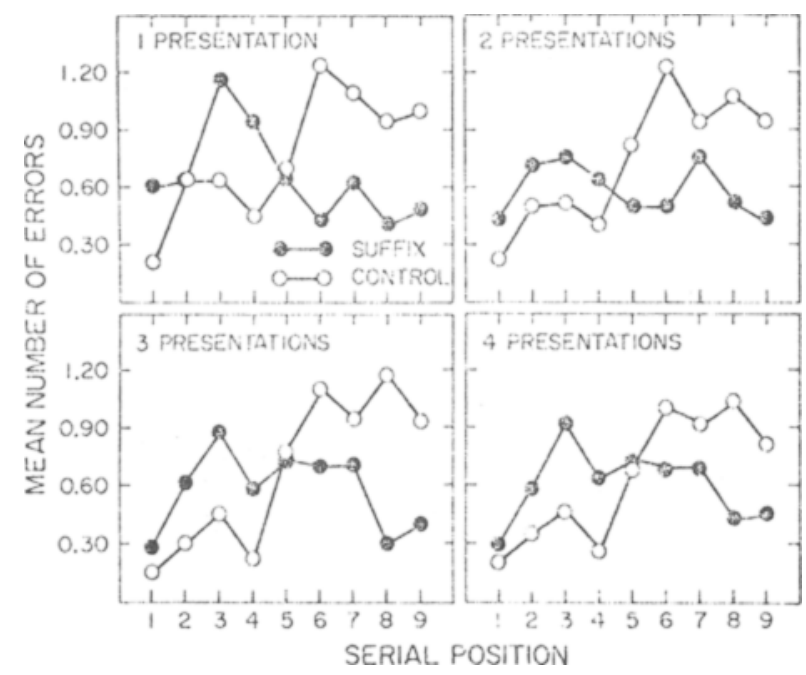

Fig. 2. Mean number of acoustic confusion errors as a function of serial position. probabilities at each list position. For example, an omitted letter at one position may lead to position errors at other positions, if the $\mathrm{S}$ does not leave a blank in his recall protocol for the omitted letter.

Repetition proved to be an effective variable with respect to performance at all serial positions in recall. However, the suffix effect did not change in magnitude with repetition. The inference to be drawn is that the precategorical acoustic trace does not benefit by repetition, as do postcategorical traces. This conclusion needs qualification, since the interval between list presentation was approximately $35 \mathrm{sec}$. Hence, the present result implies that within $35 \mathrm{sec}$ of its establishment in memory, the precategorical acoustic trace must decay to a point where it cannot be strengthened by repetition. At some time interval within the useful life of the PAS trace, it might well be possible to increment its strength by repetition. Nonetheless, the present results indicate important functional differences between PAS codes and STS codes.

\section{REFERENCES}

Craik, F. I. M., \& Lockhart, R. S. Levels of processing: A framework for memory research. Journal of Verbal Learning $\&$ Verbal Behavior, 1972, 6, 671-684.

Crowder, R. G. Improved recall for digits with delayed recall cues. Journal of Experimental Psychology, 1969, 82, 258-262.

Crowder, R. G., \& Morton, J. Precategorical acoustic storage (PAS). Perception \& Psychophysics, 1965, 5, 565-573.

Hebb, D. O. Distinctive features of learning in the higher animal. In J. F. Delafresnage (Ed.), Brain mechanisms and learning. New York: Oxford University Press, 1961. Pp. 37-46.

Melton, A. W. Implications of short-term memory for a general theory of memory. Journal of Verbal Learning \& Verbal Behavior, 1963, 2, 1-21.

Sperling, G. The information available in brief visual presentation. Psychological Monographs, 1960, 74(Whole No. 11).

(Received for publication September 24, 1973; accepted October 1, 1973.) 